\title{
PRODUTIVIDADE DE MASSA DE FORRAGEM E PROTEÍNA BRUTA DO CAPIM MOMBAÇA IRRIGADO EM FUNÇÃO DA ADUBAÇÃO NITROGENADA
}

Marco Aurélio Factori, Paulo Claudeir Gomes Silva, Daniel Moretto Gonçalves, Antenor Scatulin Neto Scatulin Neto, Carlo Henrique Zanchetta Maratti, Carlos Sérgio Tiritan

Universidade do Oeste Paulista - UNOESTE, Faculdade de Ciências Agrárias, Presidente Prudente, SP. E-mail: nafactori@unoeste.br

\section{RESUMO}

O capim mombaça (Panicum maximum Jacq.) é considerado uma das forrageiras tropicais mais produtivas à disposição dos pecuaristas sendo que o uso de adubação nitrogenada associado a irrigação pode aumentar a produtividade das plantas. Para tanto, o objetivo do trabalho foi avaliar o efeito de doses crescentes de nitrogênio em capim mombaça irrigado em relação à altura de corte, produção de massa verde e seca e porcentagem de proteína bruta nas folhas. O experimento foi conduzido na Chácara da Zootecnia do Campus II da Universidade do Oeste Paulista - UNOESTE, situada no município de Presidente Prudente/SP. O experimento foi conduzido, iniciando-se no início de verão (novembro). Para realização do experimento foram utilizados $3.480 \mathrm{~m}^{2}$ de área com capim mombaça já implantado. O experimento constou de 6 tratamentos (Doses de Nitrogênio) em delineamento em blocos casualizados que foram distribuídas em 4 blocos de $870 \mathrm{~m}^{2}$, com seis parcelas de $145 \mathrm{~m}^{2}$ (1 repetição por bloco) sendo irrigadas com aspersores tipo canhão com lâmina de água de $21 \mathrm{~mm}$ semanal ( $3 \mathrm{~mm}$ por dia). Os tratamentos utilizados no experimento foram: T1 - $0 \mathrm{~kg} \mathrm{ha}^{-1}$ de N (controle); T2 - $50 \mathrm{~kg} \mathrm{ha}^{-1} \mathrm{de} \mathrm{N}$; T3 - 100 $\mathrm{kg} \mathrm{ha}^{-1} \mathrm{de} \mathrm{N}$; T4 - $200 \mathrm{~kg} \mathrm{ha}^{-1} \mathrm{de} \mathrm{N}$; T5 - 300 $\mathrm{kg} \mathrm{ha}^{-1}$ de N e T6 - $400 \mathrm{~kg} \mathrm{ha}^{-1}$ de N. O nitrogênio foi fornecido usando-se como fonte a ureia. A aplicação do $\mathrm{N}$ foi realizada a lanço manualmente sendo as doses distribuídas a cada 30 dias (período de descanso do capim utilizado) proporcionalmente aos tratamentos utilizados. Houveram diferenças significativas para a produtividade de massa verde (MV), massa seca (MS) e proteína bruta (PB) em função dos cortes utilizados em função da dosagens de N. Para a produção acumulada de MV e MS, foram diferentes os valores em relação a todos as dosagens utilizadas sendo superior a dosagem de 100,300 e $400 \mathrm{~kg} \mathrm{ha}^{-1} \mathrm{de} \mathrm{N}$. Para a produtividade de PB, foram superiores os tratamentos de 300 e $400 \mathrm{~kg}$ de N. A utilização da dosagem de $300 \mathrm{~kg}$ de nitrogênio por hectare em pastagem de capim mombaça irrigado proporcionou melhores produtividades de massa verde, bem como melhores teores de proteína bruta da parte aérea e produtividade dos mesmos.

Palavras-chave: altura da forragem; irrigação; forragem; nitrogênio; Panicum.

\section{DRY MATTER YIELD FORAGE AND CRUDE PROTEIN OF MOMBAÇA GRASS IRRIGATED IS FUNCTION OF NITROGEN FERTILIZATION}

\begin{abstract}
Mombaça grass (Panicum maximum Jacq.) Is considered one of the most productive tropical forages available to cattle ranchers and the use of nitrogen fertilization associated with irrigation can increase the productivity of the plants. The objective of this work was to evaluate the effect of increasing nitrogen doses on irrigated Mombaça grass in relation to cutting height, green and dry mass production and percentage of crude protein in the leaves. The experiment was conducted at the Campus II Zootechny of the University do Oeste Paulista - UNOESTE, located in the municipality of Presidente Prudente / SP. The experiment was conducted, beginning in early summer (November). For the accomplishment of the experiment were used $3,480 \mathrm{~m} 2$ of area with the Mombaça grass already implanted. The experiment consisted of 6 treatments (Nitrogen Doses) in a randomized block design that were distributed in 4 blocks of $870 \mathrm{~m} 2$, with six plots of $145 \mathrm{~m} 2$ ( 1 repetition per block), being irrigated with cannon - type sprinklers with a water depth of $21 \mathrm{~mm}$ per week ( $3 \mathrm{~mm}$ per day). The treatments used in the experiment were: T1 (Witness $0 \mathrm{~kg}$ per hectare of Nitrogen (N), T2 (50 kg N per hectare as urea), T3 (100 kg N per hectare), T4 N per hectare), T5 (300 kg N per hectare) and T6 (400 kg N per hectare). The application of $\mathrm{N}$ was carried out manually, with doses
\end{abstract}


distributed every 30 days (rest period of the grass used) in proportion to the treatments used. There were significant differences for the Green Mass Productivity (MG), Dry mass (DM) and Crude Protein (CP) as a function of the cuts used as a function of $\mathrm{N}$ dosages. For the accumulated production of $\mathrm{MV}$ and $\mathrm{MS}$, the values in for all dosages used being greater than the dosage of 100, 300 and $400 \mathrm{~kg}$ of $\mathrm{N}$ per hectare. The yield of $300 \mathrm{~kg}$ of nitrogen per hectare in irrigated Mombaça grassgrass yielded better yields of green mass, as well as better crude protein contents of aerial part and productivity of the same.

Keywords: forage height; forage; irrigation; nitrogen; Panicum.

\section{INTRODUÇÃO}

O capim mombaça (Panicum maximum Jacq.) é originário da África, e no Brasil, é pesquisado desde 1982 e lançado comercialmente em 1993 pela EMBRAPA (Empresa Brasileira de Pesquisa Agropecuária).

Este capim apresenta hábito de crescimento cespitoso com aproximadamente $1,65 \mathrm{~m}$ de altura. Suas folhas são longas, quebradiças, sem serosidade e com largura média de $3 \mathrm{~cm}$. As lâminas foliares, principalmente na face superior, apresentam poucos pêlos curtos e duros. As bainhas são glabras e os colmos são levemente arroxeados e a inflorescência do tipo panícula longa com ramificações secundárias longas apenas na base (CARNEVALLI, 2003).

Possui bom vigor no estabelecimento com um rápido fechamento da vegetação e alta produtividade, possui sementes de tamanho reduzido e, por isso, demanda um grau de preparo do solo e cuidados no plantio maiores do que para outras espécies forrageiras com sementes de maior volume.

Segundo Sales e Valentim (2002), a cultivar Mombaça produz aproximadamente 33 toneladas de massa seca foliar/ha/ano com cerca de $13,4 \%$ de proteína.

Atualmente, cerca de $80 \%$ das pastagens Brasileiras encontra-se em algum estágio de degradação. Uma das principais causas dessa situação está associada à perda da fertilidade do solo, sendo que um dos principais fatores limitantes na produtividade das pastagens tropicais é a deficiência do nitrogênio (N), resultando em queda acentuada na capacidade de suporte e no ganho de peso animal. Portanto, para que haja a exploração intensiva das pastagens, há necessidade de executar corretamente as adubações de manutenção.

As pastagens brasileiras são cultivadas em áreas sujeitas às variações climáticas de temperatura, de variação solar e de índice pluviométrico. A produtividade, na maioria das gramíneas tropicais, diminui quando algum desses fatores torna-se limitante.

A intensificação da prática da irrigação configura uma opção estratégica de grande alcance para aumentar a oferta de produtos destinados ao mercado interno, consolidar a afirmação comercial do Brasil num mercado internacional altamente competitivo e melhorar os níveis de produção, produtividade e renda no meio rural.

Perante o exposto, o objetivo do trabalho será avaliar o efeito de doses crescentes de nitrogênio em capim mombaça irrigado em relação à altura da planta, produção de massa verde e seca e acúmulo de nitrogênio nas folhas.

\section{MATERIAL E MÉTODOS}

O experimento foi conduzido na Chácara da Zootecnia do Campus II da Universidade do Oeste Paulista - UNOESTE, situada no município de PresidentePrudente/SP. O clima da região se classifica em Aw, com estação chuvosa no verão e estação seca no inverno.

Os dados climáticos do período são apresentados na Figura 1. Pode-se inferir que não houve dados de temperatura mínima abaixo de 15 ㅇ $\mathrm{C}$ para influenciar no crescimento forrageiro. $\mathrm{Na}$ figura 2, estão apresentados os dados de precipitação ocorridos no período experimental. (Estação meteorológica da UNOESTE). 
Figura 1. Dados de temperatura (으) máxima (TEMP MAX), média (TEMP MED) e mínima (TEMP MIN) em função dos meses do ano (janeiro a dezembro de 2016).

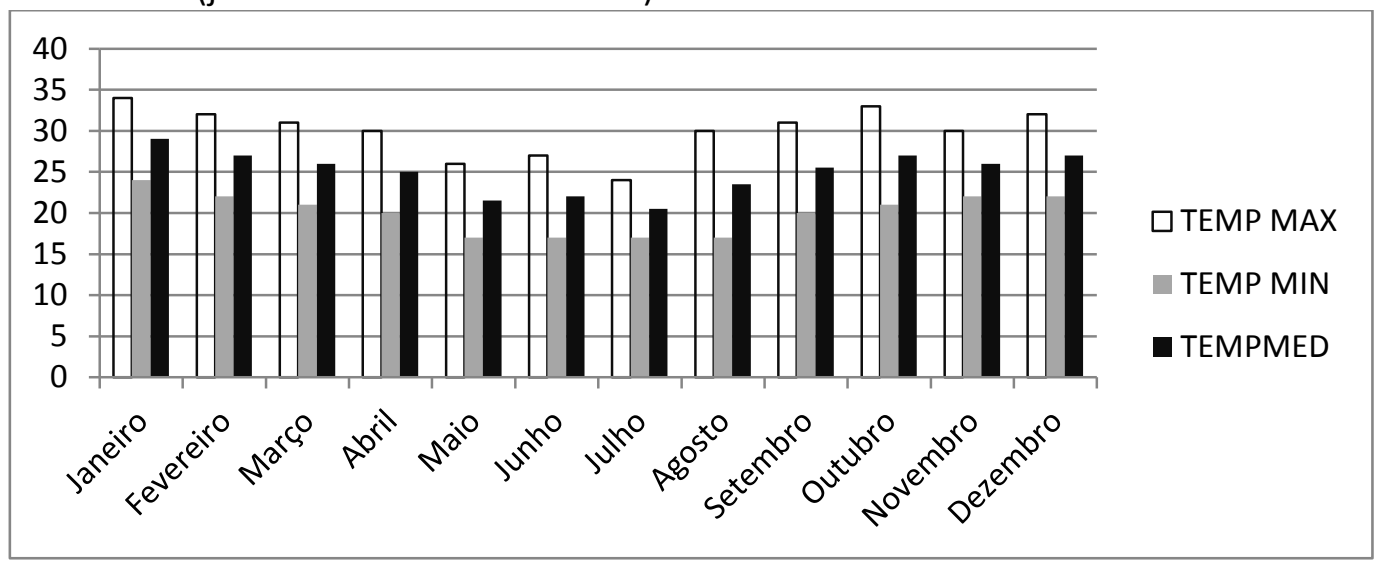

Figura 2. Dados de precipitação (em $\mathrm{mm}$ ) em função dos meses do ano durante o período experimental. (janeiro a dezembro de 2016).

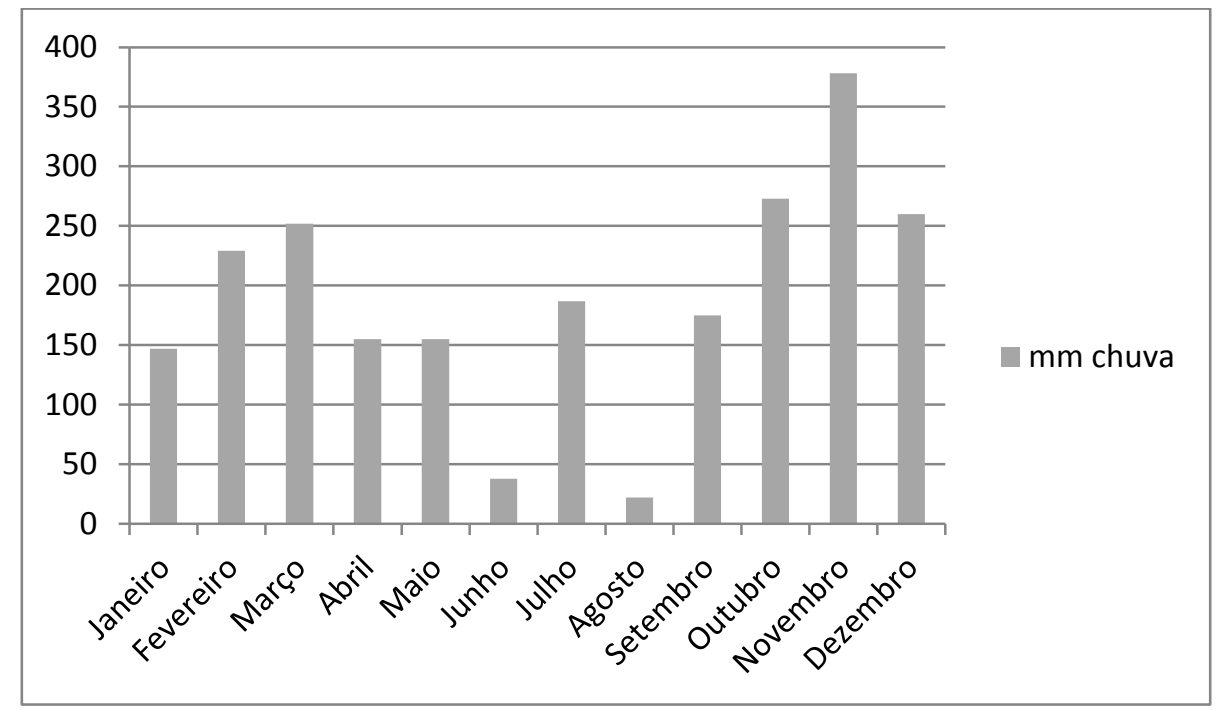

O início do experimento foi no mês de novembro. Como área experimental, foi utilizado uma área total de $3480 \mathrm{~m}^{2}$ de capim mombaça já previamente plantado e manejado para pastejo.0 experimento constou de 6 tratamentos (doses de nitrogênio na forma de ureia) que foram distribuídas em 4 blocos de $870 \mathrm{~m}^{2}$, com seis parcelas de $145 \mathrm{~m}^{2}$ ( 1 repetição por bloco) sendo irrigadas diariamente com aspersores tipo canhão com lâmina de água de $20 \mathrm{~mm}$ semanal. Os tratamentos utilizados no experimento foram: $\mathrm{T} 1$ - $0 \mathrm{~kg} \mathrm{ha}^{-1} \mathrm{de} \mathrm{N}$ (controle); $\mathrm{T} 2$ - $50 \mathrm{~kg} \mathrm{ha}^{-1}$ de N; T3 - $100 \mathrm{~kg} \mathrm{ha}^{-1}$ de N; T4 - $200 \mathrm{~kg} \mathrm{ha}^{-1}$ de N; T5 $300 \mathrm{~kg} \mathrm{ha}^{-1}$ de $\mathrm{N}$ e T6 - $400 \mathrm{~kg} \mathrm{ha}^{-1}$ de N. O nitrogênio foi fornecido usando-se como fonte a ureia.

Foram realizados um total de 6 cortes durante o verão, a cada 30 dias (período de descanso utilizado para o capim em estudo). Para o início do experimento, as parcelas foram cortadas e uniformizadas para recebimento dos tratamentos e adubadas proporcionalmente para cada tratamento, com doses de $\mathrm{N}$ que eram aplicadas após as coletas das amostras e uniformização da área experimental por meio do pastejo.

Antes do corte das amostras e uniformização das parcelas foram realizadas mensurações da altura das plantas utilizando-se um quadrado de $0,25 \mathrm{~m}^{2}$ medindo-se a altura da base e a ponta da planta mais alta existente dentro do quadrado, sendo este procedimento realizado em quatro pontos distintos de cada parcela.

A cada corte da forrageira, eram coletadas quatro amostras de pontos distintos de cada parcela para serem avaliadas em laboratório. Para coleta das amostras, foi 
utilizado um quadrado de 1 metro quadrado (1x1m), cortando-se toda a forragem a $0,35 \mathrm{~m}$ de altura. Após o corte toda a forragem foi pesada e determinada a produção de massa verde a cada parcela com quatro repetições por parcelas. Após a coleta do material, uma sub amostra de aproximadamente $0,500 \mathrm{~kg}$ foi coletada para cada sub amostra para determinação da matéria parcialmente seca em estufa de ventilação forçada a $65^{\circ} \mathrm{C}$ por 48 horas segundo Lacerda et al. (2009).

As produtividades de massa verde (MV), massa seca (MV) e proteína bruta (PMV) foram mensuradas multiplicando-se os teores encontrados de cada amostra pela produção de massa verde por metro quadrado e extrapolando-se para um hectare $\left(10.000 \mathrm{~m}^{2}\right)$

Uma sub amostra foi retirada de cada amostra para determinação da porcentagem de Proteína Bruta nas folhas, sendo realizada pelo método semimicro Kjeldhal, segundo a Association of Official Analytical Chemists (1995).

O delineamento experimental utilizado foi o em blocos ao acaso com uma repetição por bloco. As variáveis analisadas para o capim mombaça em cada tratamento foram submetidos ao programa estatístico SISVAR (SILVA, 2011) utilizando-se o teste de Tukey a $1 \%$ de probabilidade para comparação das médias.

\section{RESULTADOS E DISCUSSÃO}

Pode-se observar na Tabela 1 que a altura do capim mombaça nos quatro primeiros cortes e no último corte não diferiu de acordo com as doses de nitrogênio aplicadas. Entretanto, no quinto corte realizado houve diferença significativa, sendo que as doses N300 e $400 \mathrm{~kg}$ $\mathrm{ha}^{-1}$ proporcionaram maiores incrementos na altura da forrageira em relação às demais.

Tabela 1. Altura de plantas de capim mombaça irrigado em seis cortes em função das dosagens de Nitrogênio (N) aplicadas

\begin{tabular}{ccccccc}
\hline \multirow{2}{*}{$\begin{array}{c}\text { Dosagens de } \mathrm{N} \\
\left(\mathrm{kg} \mathrm{ha}^{-1}\right)\end{array}$} & 10 Corte & 20 Corte & 30 Corte & 40 Corte & 50 Corte & 60 Corte \\
\cline { 2 - 7 } & 0,37 & 0,59 & 0,62 & 0,51 & $0,50 \mathrm{~d}$ & 0,56 \\
50 & 0,41 & 0,55 & 0,60 & 0,69 & $0,59 \mathrm{~cd}$ & 0,53 \\
100 & 0,64 & 0,59 & 0,61 & 0,63 & $0,90 \mathrm{ab}$ & 0,54 \\
200 & 0,62 & 0,60 & 0,63 & 0,60 & $0,62 \mathrm{bcd}$ & 0,63 \\
300 & 0,69 & 0,48 & 0,55 & 0,65 & $0,79 \mathrm{abc}$ & 0,55 \\
400 & 0,45 & 0,56 & 0,60 & 0,69 & $0,95 \mathrm{a}$ & 0,57 \\
\hline C.V.(\%) & 40,80 & 13,28 & 11,38 & 23,82 & 17,23 & 14,13 \\
\hline
\end{tabular}

* Médias seguidas de mesma letra na coluna não diferem estatisticamente pelo teste Tukey $(p<0,01)$.

Sendo o Nitrogênio o elemento mais importante para o crescimento das forrageiras, as dosagens de $\mathrm{N}$ com valores de 300 e $400 \mathrm{~kg} \mathrm{ha}^{-1}$ mostraram-se importantes para o incremento da altura das plantas na situação do presente experimento. Sendo assim, juntamente com a matéria orgânica do solo proporcionaram a planta maior aporte de nutrientes e esta pode expressar seu potencial forrageiro em relação ao parâmetro altura da planta.

Em condições de maior permanência da água da chuva ou da irrigação, o nitrogênio adicionado ao solo pode difundir-se para o interior dos agregados maiores, circunstâncias em que, apesar das restrições na absorção do nutriente pela planta e do aumento do processo de desnitrificação, a lixiviação do nitrogênio na forma de nitrato pode ser bastante reduzida (SILVA et al., 2005).

Com relação à produtividade de massa verde por hectare do capim mombaça no primeiro, segundo, quarto e quinto cortes não diferiram de acordo com as doses de nitrogênio aplicadas. No terceiro corte a dose de $400 \mathrm{~kg} \mathrm{ha}^{-1}$ diferiu significativamente do tratamento controle e dos demais tratamentos, enquanto que no sexto corte a dosagem de $400 \mathrm{~kg} \mathrm{ha}^{-1}$, embora semelhante ás dosagens de 250 e $300 \mathrm{~kg} \mathrm{ha}^{-1}$ foi superior a todos os demais tratamentos (Tabela 2). 
Tabela 2. Produtividade de massa verde $\left(\mathrm{kg} \mathrm{ha}^{-1}\right)$ de seis cortes realizados em capim Mombaça irrigado em função das dosagens de Nitrogênio $(\mathrm{N})$ aplicadas

\begin{tabular}{ccccccc}
\hline $\begin{array}{c}\text { Dosagens de } \mathrm{N} \\
\left(\mathrm{kg} \mathrm{ha}^{-1}\right)\end{array}$ & Massa Verde $\left(\mathrm{kg} \mathrm{ha}^{-1}\right)$ \\
\cline { 2 - 7 } & 1 Corte & 20 Corte & 3 Corte & 40 Corte & 50 Corte & 60 Corte \\
\hline 0 & 4820 & 4680 & $4200 \mathrm{~b}$ & 4492 & 3728 & $3280 \mathrm{~b}$ \\
50 & 8408 & 6172 & $7140 \mathrm{ab}$ & 5660 & 3488 & $3120 \mathrm{~b}$ \\
100 & 14840 & 5016 & $5300 \mathrm{ab}$ & 9360 & 1464 & $2936 \mathrm{~b}$ \\
200 & 7680 & 4120 & $4848 \mathrm{ab}$ & 6224 & 5968 & $3844 \mathrm{ab}$ \\
300 & 12612 & 5012 & $5740 \mathrm{ab}$ & 11352 & 7892 & $4924 \mathrm{ab}$ \\
400 & 8000 & 9140 & $8908 \mathrm{a}$ & 11492 & 7912 & $5920 \mathrm{a}$ \\
\hline C.V.(\%) & 57,69 & 39,42 & $33,69 *$ & 49,42 & 36,77 & $26,87^{*}$ \\
\hline
\end{tabular}

* Médias seguidas de mesma letra na coluna não diferem estatisticamente pelo teste Tukey $(p<0,01)$.

Dentre os nutrientes minerais das plantas, o nitrogênio é o maior limitante da produtividade agrícola por participar da estrutura de inúmeros compostos vitais aos vegetais e ser 0 mais escasso no solo. A principal fonte de nitrogênio para as plantas é a matéria orgânica do solo, além de fornecedora de elementos, como fósforo e enxofre e de vários micronutrientes (MENEZES et al., 2013). Por este motivo, se a matéria orgânica do solo for limitante ao desenvolvimento, o incremento do $\mathrm{N}$ na forma de adubação mineral ou orgânica é fator imprescindível para o aumento da produtividade de massa verde da forrageira.

$\mathrm{Na}$ Tabela 3 pode ser observado que o acúmulo de massa seca na parte aérea de capim mombaça nos três primeiros cortes não diferiu de acordo com as doses de nitrogênio aplicadas, enquanto que nos demais cortes realizados houveram diferenças significativas.

No quarto corte realizado, a dosagem de $300 \mathrm{~kg}$ de nitrogênio por hectare foi a que apresentou maior acúmulo de massa seca em relação aos demais tratamentos empregados. Contudo, no quinto corte, esta mesma dosagem, embora semelhante a todos os cortes, excetuando-se o controle de $0 \mathrm{~kg} \mathrm{ha}^{-1}$ por hectare, foi o superior, exclusivamente, ás demais doses. No sexto corte, o maior acúmulo de massa seca da forrageira foi registrado na área onde foram aplicados $400 \mathrm{~kg}$ de nitrogênio ha ${ }^{-1}$ por hectare, diferindo significativamente das áreas que receberam apenas 0, 50, 100 e $200 \mathrm{~kg}$ de $\mathrm{N}^{-1}{ }^{-1}$ (Tabela 3).

Tabela 3. Produtividade de massa seca $\left(\mathrm{kg} \mathrm{ha}^{-1}\right)$ de seis cortes realizados em capim Mombaça irrigado em função das dosagens de Nitrogênio (N) aplicadas

\begin{tabular}{ccccccc}
\hline $\begin{array}{c}\text { Dosagens de } \mathrm{N} \\
\left(\mathrm{kg} \mathrm{ha}^{-1}\right)\end{array}$ & 10 Corte & 20 Corte & 30 Corte & 40 Corte & 50 Corte & 60 Corte \\
\hline 0 & 2080 & 1360 & 1464 & $1264 \mathrm{~b}$ & $1500 \mathrm{~b}$ & $1384 \mathrm{ab}$ \\
50 & 3600 & 1600 & 2224 & $1132 \mathrm{~b}$ & $2000 \mathrm{ab}$ & $1264 \mathrm{~b}$ \\
100 & 6360 & 1800 & 1688 & $1612 \mathrm{~b}$ & $2540 \mathrm{ab}$ & $1288 \mathrm{~b}$ \\
200 & 3320 & 1736 & 1484 & $1504 \mathrm{~b}$ & $1916 \mathrm{ab}$ & $1528 \mathrm{ab}$ \\
& & & & & & \\
300 & 5400 & 1400 & 1808 & $3076 \mathrm{a}$ & $2680 \mathrm{a}$ & $1760 \mathrm{ab}$ \\
400 & 3440 & 1708 & 2708 & $2004 \mathrm{~b}$ & $2400 \mathrm{ab}$ & $2096 \mathrm{a}$ \\
\hline C.V.(\%) & 57,77 & 13,90 & 35,62 & $26,77^{*}$ & $22,01 *$ & $22,05^{*}$ \\
\hline
\end{tabular}

*Médias seguidas de mesma letra na coluna não diferem estatisticamente pelo teste Tukey $(p<0,01)$.

O critério na utilização de doses de adubos nitrogenados é de grande importância, já que a sua utilização pode acelerar o processo de emissão de gases de efeito estufa, uma vez que em contato com o solo esses passam por reações mediadas por microrganismos que podem levar à formação de $\mathrm{N}_{2} \mathrm{O}$ (TEIXEIRA et al., 2006). Tendo em vista a baixa fertilidade dos solos, é necessário que estabeleça níveis médios de fertilidade a serem alcançados, como possibilidade de viabilização técnica e econômica, dada a gradual capacidade de resposta dos solos no processo de recuperação (CORREA, 1997).

A porcentagem de proteína bruta na parte aérea de capim mombaça no primeiro, quarto e quinto cortes, não diferiu de acordo com 
as doses de nitrogênio aplicadas. No segundo corte realizado na forrageira, a área controle apresentou maior valore em relação às áreas onde receberam adubação nitrogenada de 50 e $200 \mathrm{~kg} \mathrm{ha}^{-1}$ (Tabela 5).

No terceiro corte da forrageira houve diferença significativa entre as percentagens de proteína bruta presente na parte aérea do capim mombaça, sendo que a área que recebeu adubação de $300 \mathrm{~kg}$ de nitrogênio $\mathrm{ha}^{-1}$ apresentou maior teor de nitrogênio em relação ao tratamento que recebeu adubação de apenas $100 \mathrm{~kg}$ de nitrogênio $\mathrm{ha}^{-1}$, embora semelhantes ao tratamento de 100, 200 e $300 \mathrm{~kg} \mathrm{ha}^{-1}$ de N. Já no sexto corte, o tratamento adubado com 300 $\mathrm{kg} \mathrm{ha}^{-1}$ de $\mathrm{N}$ foi semelhante à dosagem de $400 \mathrm{~kg}$ $\mathrm{ha}^{-1}$ e superiores aos demais tratamentos, embora mais uma vez, o tratamento de $300 \mathrm{~kg}$ $\mathrm{ha}^{-1}$ assumir valor superior aos demais (Tabela 4).

Tabela 4. Porcentagem de Proteína Bruta na parte aérea de capim mombaça irrigado, realizado em seis cortes em função das dosagens de Nitrogênio (N) aplicadas

\begin{tabular}{ccccccc}
\hline $\begin{array}{c}\text { Dosagens de } \mathrm{N} \\
\left(\mathrm{kg} \mathrm{ha}^{-1}\right)\end{array}$ & \multicolumn{7}{c}{ (\%) } \\
\cline { 2 - 7 } & 10 Corte & 20 Corte & 30 Corte & 40 Corte & 50 Corte & 60 Corte \\
\hline 0 & 16,8 & $19,3 \mathrm{a}$ & $14,0 \mathrm{ab}$ & 15,7 & 15,7 & $12,5 \mathrm{~b}$ \\
50 & 17,3 & $11,6 \mathrm{~b}$ & $12,2 \mathrm{~b}$ & 17,8 & 14,9 & $15,4 \mathrm{~b}$ \\
100 & 15,5 & $12,5 \mathrm{ab}$ & $17,0 \mathrm{ab}$ & 19,3 & 15,8 & $15,0 \mathrm{~b}$ \\
200 & 16,1 & $11,6 \mathrm{~b}$ & $16,5 \mathrm{ab}$ & 21,9 & 16,2 & $15,1 \mathrm{~b}$ \\
300 & 17,8 & $12,0 \mathrm{ab}$ & $19,3 \mathrm{a}$ & 22,6 & 19,3 & $24,9 \mathrm{a}$ \\
400 & 19,3 & $17,4 \mathrm{ab}$ & $14,5 \mathrm{ab}$ & 17,9 & 18,0 & $20,7 \mathrm{ab}$ \\
\hline C.V.(\%) & 25,85 & $24,03^{*}$ & $17,53^{*}$ & 21,22 & 12,91 & $21,43 *$ \\
\hline
\end{tabular}

*Médias seguidas de mesma letra na coluna não diferem estatisticamente pelo teste Tukey $(p<0,01)$.

Para a aplicação de fertilizantes nitrogenados no solo, este deve ser feita de acordo com a necessidade da planta a ser cultivada. A determinação desta necessidade no solo e na planta é importante no sentido de aperfeiçoar a utilização do nitrogênio pela cultura, minimizando os custos com fertilizante nitrogenados além de evitar o processo de poluição ambiental (FERREIRA et al., 2006).

Quando normalmente se utiliza doses elevadas de adubos nitrogenados, estes podem proporcionar maior lixiviação do elemento na solução do solo, diminuindo o aproveitamento do nutriente pelas plantas. Sendo que os maiores fluxos de perdas do nitrogênio mineral para a atmosfera ocorrem após 44 horas de sua aplicação, mas quando se utiliza ureia revestida com polímeros e composto orgânico ocorrem menores perdas de amônia por volatilização (LORENSINI et al., 2012).
Na tabela 5 estão apresentados os dados acumulados durante o período experimental em relação ás produtividades de massa verde (MV), massa seca (MS) e proteína bruta (PB). Pode-se observar que para os três parâmetros houve efeito significativo entre as dosagens de $\mathrm{N}$ utilizadas. Para a produção de MV, foram diferentes os valores em relação a todos as dosagens utilizadas sendo superior a dosagem de $400 \mathrm{~kg}$ de $\mathrm{N}$ por hectare. A produção de MS também se comportou de forma diferente, com o tratamento de 100,300 e $400 \mathrm{~kg}$ por hectare como os superiores, no entanto, para a produtividade de $\mathrm{PB}$ por hectare, em $\mathrm{kg} \mathrm{ha}^{-1}$ foram superiores os tratamentos de 300 e $400 \mathrm{~kg}$ de N. Para a produtividade de PB, e MV e MS os menores valores foram assumidos por menores dosagens de $\mathrm{N}$. 
Tabela 5. Teores de matéria seca (\%) e produtividade acumulada de massa verde, massa seca e proteína bruta em função das dosagens de nitrogênio.

\begin{tabular}{ccccc}
\hline \multirow{2}{*}{$\begin{array}{c}\text { Dosagens de } \mathrm{N} \\
\left(\mathrm{kg} \mathrm{ha}^{-1}\right)\end{array}$} & $\begin{array}{c}\text { Teores de Matéria } \\
\text { Seca }\end{array}$ & Massa verde & Massa seca & $\begin{array}{c}\text { Kg de Proteína } \\
\text { Bruta }\end{array}$ \\
\cline { 3 - 5 } & 21,2 & $36700 \mathrm{f}$ & $7788 \mathrm{c}$ & $5046 \mathrm{~d}$ \\
50 & 23,1 & $46256 \mathrm{e}$ & $10688 \mathrm{~b}$ & $6035 \mathrm{c}$ \\
100 & 26,0 & $52676 \mathrm{c}$ & $13676 \mathrm{a}$ & $6866 \mathrm{~b}$ \\
200 & 20,5 & $48720 \mathrm{~d}$ & $9984 \mathrm{~b}$ & $6899 \mathrm{~b}$ \\
300 & 18,2 & $71700 \mathrm{~b}$ & $13048 \mathrm{a}$ & $11657 \mathrm{a}$ \\
400 & 16,1 & $76696 \mathrm{a}$ & $12352 \mathrm{a}$ & $11715 \mathrm{a}$ \\
\hline C.V.(\%) & 28,00 & $33,00^{*}$ & $27,00^{*}$ & $20,00^{*}$ \\
\hline
\end{tabular}

*Médias seguidas de mesma letra na coluna não diferem estatisticamente pelo teste Tukey $(p<0,01)$.

É evidente que o aumento da dosagem de $\mathrm{N}$ aplicado aumenta a produtividade da forragem. Segundo Caielli et al. (1991), Andrade (1997) e Paciullo (1997) o incremento na produção é decorrente da aplicação de nitrogênio. No entanto, o aumento na produção de forragem, em resposta à adubação nitrogenada, implica também na aplicação de outros nutrientes, como potássio e fósforo, além da adoção de práticas adequadas de manejo.No presente estudo, pode-se inferir que a produção de $\mathrm{n}$ foi fundamental para tal incremento uma vez que as condições do solo foram equivalentes para os tratamentos.

Outra informação importante a relação lâmina foliar/colmo é de grande importância do ponto de vista nutritivo e do manejo das espécies forrageiras. Embora trabalhando com capim elefante - Napier, em diferentes doses de N, Andrade (1997) observou diferenças nesta relação lâmina foliar /colmo, implicando em diferenças significativas neste quesito. Sendo assim, no presente estudo foram detectadas diferenças em função do teor de $P B$ e produtividade da mesma.

A relação folha/colmo tem grande importância para a nutrição animal e para o manejo de plantas forrageiras, pois a maior participação de folhas ou de colmos na composição da matéria seca altera o valor nutritivo da forragem consumida. A alta relação folha/colmo representa forragem de elevado teor de proteína, digestibilidade e consumo (WILSON, 1982). No presente estudo, o $\mathrm{N}$ aplicado em função das dosagens, contribui claramente com o aumento da produtividade de $\mathrm{N}$ e com isso poderá aumentar a digestibilidade ou $\mathrm{O}$ aproveitamento de um modo geral da forrageira, embora não mencionado no presente estudo, sobretudo com o uso da irrigação.
Segundo Ribeiro (1995), há efeito da adubação nitrogenada sobre o teor de proteína das plantas. Favoretto et al. (1988), trabalhando com capim colonião adubado com 0,50 e 100 $\mathrm{kg} / \mathrm{ha}$ de $\mathrm{N}$ em capim-colonião, durante o verão (novembro-março), verificaram aumento na produção de MS, em função da elevação dos níveis de $\mathrm{N}$. No presente estudo, o aumento da dosagem de $\mathrm{N}$ aplicado refletiu significativamente sobre o aumento da produção de $M V, M S$ e $P B$, sobretudo com o uso da irrigação.

Segundo Pinheiro (2002), outro fator importante no crescimento da forragem é a água. Ao avaliar a produção do capim țanzânia irrigado, o autor observou aumento na produção com elevação das doses de $\mathrm{N}$, registrando valores de até $23.000 \mathrm{~kg} / \mathrm{ha} / \mathrm{ano}$ de MS. Benedetti et al. (2001) observaram, para o capim Tanzânia sob irrigação, cortado a cada 30 dias, produções de 5,7 t/ha de MV na época chuvosa e 2,9 t/ha na época seca, dados inferiores aos encontrados no presente estudo de até $12000 \mathrm{~kg}$ por hectare a cada corte de MV no período experimental (verão). A baixa produção de massa de forragem durante o inverno tem sido apontada como um dos fatores que mais contribuem para a baixa produtividade dos rebanhos. Podemos associar ainda, que devemos maximizar a produção de verão, uma vez que no inverno os índices serão diminuídos em função da estacionalidade, viabilizando desta forma o uso do $\mathrm{N}$ no verão.

Com certeza, o sucesso da utilização da adubação nitrogenada e a irrigação de pastagens dependerão do manejo a ser adotado uma vez que a produtividade também depende da eficiência da aplicação destes dois elementos de forma correta. Para tanto, associar a irrigação de pastagens a níveis de adubação nitrogenada depende, dentre outros da economicidade do 
uso desta ferramenta. Sendo assim, perante o exposto neste trabalho, embora os níveis mais altos de adubação proporcionarem melhores índices, a adubação de $300 \mathrm{~kg}$ pro hectare se mostrou competitiva e superior aos demais tratamentos.

\section{CONCLUSÃO}

A utilização da dose de $300 \mathrm{~kg}$ de nitrogênio por hectare em pastagem de capim mombaça irrigado proporcionou melhores produtividades de massa, bem como melhores teores de proteína bruta da parte aérea e produtividade da mesma.

\section{REFERÊNCIAS}

ANDRADE, A. C. Produtividade e valor nutritivo do Capim-Elefante (Pennisetum purpureum Schum. cv. Napier) sob diferentes doses de nitrogênio e potássio.1997. 52 f. Dissertação (Mestrado) - Universidade Federal de Viçosa, Viçosa-MG, 1997.

ASSOCIATION OF OFFICIAL ANALYTICAL CHEMISTS. Official methods of analysis.16. ed. Washington, 1995.

BENEDETTI, E.; COLMANETTI, A.L.; DEMETRIO, R.A. Produção e composição bromatológica do capim Panicum maximum Jacq. cv. Tanzânia irrigado em solo de cerrado. Veterinária Notícias, v.27, n.2, p.123-128, 2001.

CAIELLI, E. L.; BONILHA NETO, L. M.; LOURENÇO, A. J. Avaliação agronômica e qualitativa de pastos de capim- elefante Napier (Pennisetum purpureum Schum.) fertilizados com nitrogênio ou consorciados com leguminosas tropicais para produção de carne. Boletim de Indústria Animal, Nova Odessa, v. 48, n. 1, p. 63-76, 1991.

CARNEVALLI, R. A. Dinâmica da rebrotação de pastos de capim - Mombaça submetidos a regimes de desfolhação intermente. Piracicaba, 2003. 136 p. Tese (Doutorado) - Escola Superior de Agricultura "Luiz de Queiroz", Universidade de São Paulo, Piracicaba-SP, 2003.

CORREA, L. A. Produção intensiva de carne bovina a pasto. São Carlos: EMBRAPA - Pecuária Sudeste, 1997.

FAVORETTO, V.; RODRIGUES, L.R.A.; TUPINAMBÁ, C.F. Estudo do nitrogênio na produção e composição bromatológica do capim-colonião e seus aspectos econômicos. Científica, v.16, n.1, p.71-78, 1988.

FERREIRA, M. M. M.; FERREIRA, G. B.; FONTES, P. C. R.; DANTAS, J. P. Índice SPAD e teor de clorofila no limbo foliar do tomateiro em função de doses de nitrogênio e da adubação orgânica, em duas épocas de cultivo. Ceres, v. 53, n. 305, p.83-92, 2006.

LACERDA, M.J.R.; FREITAS, K.R.; SILVA, J.W. Determinação da matéria seca deforrageiras pelos métodos de microondas e convencional. Bioscience Journal, v.25, n.3, p.185-190, 2009.

LORENSINI, F.; CERETTA, C. A.; GIROTTO, E.; CERINI, J. B.; LOURENZI, C. R.; CONTI, L.; TRINDADE, M. M.; MELO, G. W.; BRUNETTO, G. Lixiviação e volatilização de nitrogênio em um Argissolo cultivado com videira submetida à adubação nitrogenada. Ciência Rural, v. 42, n. 7, p. 1173-1179, 2012.

https://doi.org/10.1590/S0103$\underline{84782012005000038}$

MENEZES, L. F. G.; RONSANI, R.; PAVINATO, P. S.; BIESEK, R. R; SILVA, C. E. K.; MARTINELLO, C.; CAPPELLESSO, B.; SILVEIRA, M. F. Produção, valor nutricional e eficiências de recuperação e utilização do nitrogênio de silagens de milho sob diferentes doses de adubação nitrogenada. Semina: Ciências Agrárias, v. 34, n. 3, p. 1353-1362, 2013.

https://doi.org/10.5433/16790359.2013v34n3p1353

PACIULLO, D. S. C. Produtividade e valor nutritivo do capim-elefante Anão Pennisetum purpureum Schum cv. MOTT) ao atingir 80 e 120 cm de altura sob diferentes doses de nitrogênio. 1997. Dissertação (Mestrado) - Universidade Federal de Viçosa, Viçosa-MG, 1997.

PINHEIRO, V.D. Viabilidade econômica da irrigação de pastagem de capim Tanzânia em diferentes regiões do Brasil. 2002. 85 p. Dissertação (Mestrado) - Escola Superior de Agricultura "Luiz de Queiroz", Piracicaba-SP, 2002.

RIBEIRO, K. G. Rendimento forrageiro e valor nutritivo do capim elefante "Anão", sob cinco doses de nitrogênio ao atingir 80 e $120 \mathrm{~cm}$ de 
altura. 1995. 60 f. Dissertação (Mestrado) Universidade Federal de Viçosa, Viçosa-MG, 1995.

SALES, M. F. L.; VALENTIM, J. F. Capim Mombaça - formação e manejo de pastagens no Acre. Rio Branco: Embrapa, 2002.

SILVA, F. A. S. Assistat. Versão 7.6 beta. 2011. Disponível em: <http://www.assistat.com/indexp.html.>

SILVA, E.C.; BUZETTI, S.; GUIMARÃES, G.L.; LAZARINI, E.; SÁ, M.E. Doses e épocas de aplicação de nitrogênio na cultura do milho em plantio direto sobre Latossolo Vermelho. Revista Brasileira de Ciência do Solo, v. 29, p. 353-362, $2005 . \quad$ https://doi.org/10.1590/50100$\underline{06832005000300005}$

TEIXEIRA, F. C. P.; REINERT, F.; RUMJANEK, N. G.; BODDEY, R. M. Quantification of the contribution biological nitrogen fixation to Cratylia mollis using the $15 \mathrm{~N}$ natural abundance technique in the semi-arid Caatinga region of Brazil. Soil Biology and Biochemistry, v. 38, p. 1989-1993, 2006.

https://doi.org/10.1016/j.soilbio.2005.11.013

WILSON, J. R. Environmental and nutricional factors affecting herbage quality. In: HACKER, J. B. (Ed.). Nutritional limits to animal production from pastures. Farnham Royal: CAB, 1982. p. 111-113.

Recebido para publicação em 20/06/2017

Revisado em 12/12/2017

Aceito em 24/01/2018 